\title{
La resistencia y opresión de la iglesia católica en Chile:1973-1990
}

Resistance and oppression towards the Catholic Church in Chile: 1973-1990

\section{A resistência e opressão da Igreja Católica no}

Chile:1973-1990

\author{
Elizabeth Abigail Sampson \\ The University of the West Indies, St. Augustine \\ Trinidad and Tobago \\ ORCID: 0000-0002-0899-5677 \\ Recibido: 27/09/2020 - Aceptado:20/08/2020
}

El régimen pinochetista duró diecisiete años en Chile. Durante ese período, la iglesia católica experimentaba muchos desafíos con el dictador, Augusto Pinochet. Es notable que las múltiples perspectivas dentro de la iglesia católica chilena contribuyeron a los retos ya enfrentados por esa organización religiosa. La iglesia católica era como una contracultura y luchaba contra la opresión religiosa. Este artículo destaca los varios métodos de resistencia de la iglesia católica chilena (1973-1990).

Palabras claves: Iglesia católica, dictaduras latinoamericanas, opresión religiosa, resistencia, contracultura, Chile

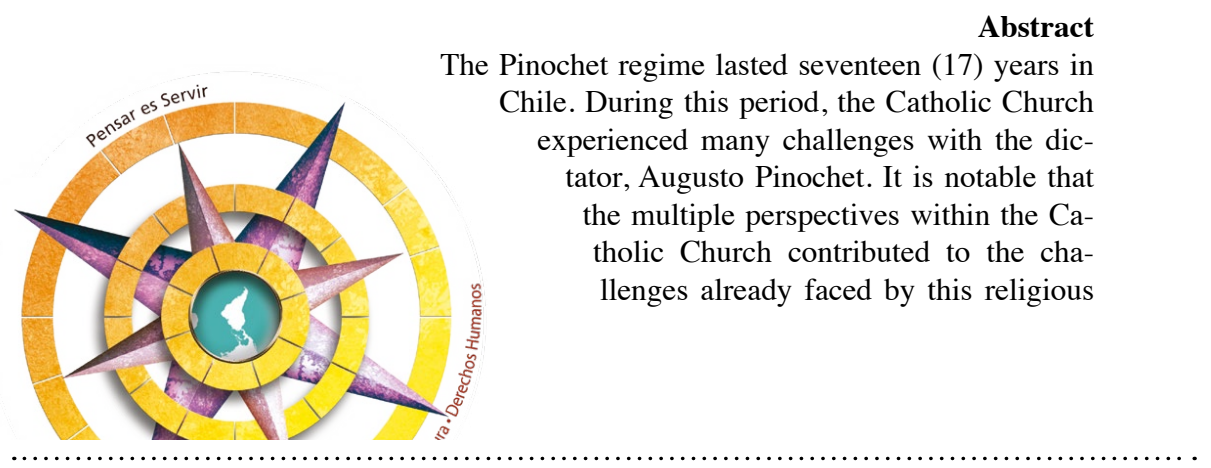

Doi: https://doi.org/10.15359/tdna.37-69.4 
organization. The Catholic Church was a counterculture and fought against religious oppression. This article highlights the various resistance methods by the Catholic Church (1973-1990).

Keywords: Catholic Church, Latin American dictatorships, religious oppression, resistance, counterculture, Chile

Resumo

O regime Pinochet durou dezessete anos no Chile. Durante esse período, a Igreja Católica passou por muitos desafios sob o ditador Augusto Pinochet. É notável que as múltiplas perspectivas dentro da Igreja Católica chilena contribuíram para os desafios já enfrentados por essa organização religiosa. A Igreja Católica era como uma contracultura e lutava contra a opressão religiosa. Este artigo destaca os vários métodos de resistência da Igreja Católica Chilena (1973-1990).

Palavras chave: greja Católica, ditaduras latino-americanas, opressão religiosa, resistência, contracultura, Chile

\section{Antecedentes históricos}

Las políticas de Pinochet se extendían a la iglesia en Chile. Usualmente cuando los dictadores asumen el poder, un organismo religioso sirve como legitimación moral. Por otro lado, puede funcionar como una fuente de denuncia. Para algunos arzobispos y obispos, Pinochet era un Salvador. En cambio, algunos líderes religiosos pensaban que Pinochet era un demonio/ opresor. Seguidamente se examina la relación de Pinochet y la iglesia chilena.

El Estado y la iglesia en Chile funcionan como una unidad antes de 1925. Lene Sjørup (2006) enfatiza que la constitución de 1925 separó la iglesia y el Estado en Chile y la nueva constitución de Pinochet no alteró esto. (p.43). La división del Estado y la iglesia conducía a varias subculturas y contraculturas en Chile. Jorge Jiménez (1997) ofrece las definiciones de subcultura y contracultura. Jiménez (1997) define una subcultura como “...un movimiento social cuyas manifestaciones $\mathrm{y}$ aspiraciones permanecen en un ámbito socialmente limitado, marginal" (p. 171). Por otro lado, una contracultura es "... una subcultura que transforma cuando su presencia es significativa y amenaza con provocar cambios importantes en la cultura tradicional" (Jiménez, 1997, p. 171). La iglesia evangélica podía transformarse de contracultura a una subcultura en Chile.

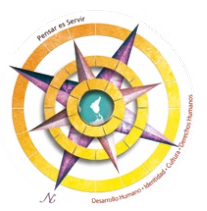


El 11 de septiembre de 1973 Pinochet apareció como un salvador de Chile. Él utilizaba muchas frases religiosas para 'lavar el cerebro' de la ciudadanía en sus discursos. Álvaro Ramis (2013) destaca que el golpe de estado se interpreta como una respuesta de Dios ante una catástrofe social y política. Antes de la administración pinochetista, Salvador Allende era presidente y líder socialista. Ramis (2013) también menciona que hay personas que opinaban que la represión violenta era un sacrificio necesario a la misión de las Fuerzas Armadas. Pinochet sostenía, en 1974, que el pueblo chileno oraba por su salvación (Ramis, 2013). Él era como un ángel de luz para la iglesia católica y necesitaba la iglesia evangélica confiar en su liderazgo.

El derrocamiento de Allende señaló una victoria religiosa en Chile (Sjørup, 2006). Había una guerra entre la civilización occidental y ateísmo, y el régimen de Pinochet trataba de garantizar la civilización occidental. Allende era socialista y muchas personas opinan que los socialistas eran ateos. Por eso, una población religiosa como la iglesia católica de Chile veía en Allende una amenaza a su religión. Allende simbolizaba 'progreso' y una nueva perspectiva. La iglesia católica simbolizaba 'tradición'. Santiago Castro Gómez (2000) destaca que la modernidad era generadora de alteridades. Con la modernidad hay una generación de conceptos binarios: barbarie y civilización, tradición y modernidad, comunidad y sociedad, mito y ciencia, solidaridad orgánica y solidaridad mecánica, pobreza y desarrollo (Castro Gómez, 2000).

Hay elementos del antiguo y del nuevo testamento de la Biblia que Pinochet utilizó en su discurso para mostrar que él era el protector y mártir del cristianismo en Chile. Sjørup (2006) añadió que Pinochet era un hombre de Dios. "...divine hero who led the chosen people and therefore God's special protector" (Sjørup, 2006, p. 47). Sjørup no es el único autor que menciona el uso de referencias bíblicas en el discurso de Pinochet. Pablo Ortúzar Madrid, Carolina Tomic López y Sebastián Huneeus Valenzuela (2009) destacan las referencias religiosas que Pinochet utilizó para legitimar su régimen. "Guerra santa", "sacrificio" y "Cristo en la cruz entre ladrones" (Ortúzar Madrid, Tomic López y Huneeus Valenzuela, 2009, pp. 243-244). Pinochet utilizaba estas frases para apelar a los ciudadanos y, a la vez, prevenir denuncias/ oposición a su régimen. 
La Biblia proveía una fuente de poder y legitimidad para Pinochet.

Pinochet estableció un vínculo entre el ejército chileno y Jesucristo (Sjørup, 2006). El presidente opinaba que el ejército era como Jesucristo que nació de la línea real de David, ayudó a Dios/presidente a salvar a su pueblo escogido del mal y establecer una nueva era para el cristianismo y no para gobernar el secularismo. No obstante, Jesucristo no es la única figura bíblica que tenía un vínculo con el ejército chileno bajo la dictadura de Pinochet. La Virgen María también compartía una relación con el ejército. La Virgen del Carmen era virgen patrona del ejército con el puesto de general y un salario que fue pagado a la iglesia mayor en Maipú. En 1987, el papa Juan Pablo II asignó a la Virgen del Carmen el título de la reina de Chile. Esta Virgen convirtió en protectora especial y propiedad de Pinochet especialmente después de su intento de asesinato.

\section{El comienzo de malas relacio- nes de poder}

Las buenas relaciones entre Pinochet y la iglesia católica no duraban durante su administración. Sjørup (2006) señala que Pinochet se hacía el nuevo amigo de la iglesia evangélica / protestante cuando la iglesia católica no quería proveer un espacio para su celebración ritual. Este era el inicio de malas relaciones entre Pinochet y la iglesia católica porque él frecuentemente buscaba maneras de reprimir y silenciar la iglesia católica. El silenciamiento de subalternos no es nuevo. De hecho, es una manera para mantener el poder. Santiago Castro Gómez y Ramón Grosfoguel (2007) revelan que hay jerarquías de poder. Estas jerarquías son: etnoracial, espiritual, epistémica, sexual y de género (Castro Gómez y Ramón Grosfoguel, 2007). Esta jerarquización conduce a discriminación, opresión y creación de subalternos. Pinochet se establecía como un dios. El dictador relegó la iglesia católica al sirviente y, a la vez, subalterno, cuando él no podía recibir la ayuda moral de esta organización religiosa.

\section{Métodos de opresión religiosa}

Las varias maneras en que el régimen de Pinochet oprimía a la iglesia católica están destacadas por Jorge Escalante. Una manera en que Pinochet trataba de extender su colonialidad del poder en Chile era con la vigilancia de la iglesia católica. Escalante (2006) menciona que la Dirección Nacional de Inteligencia (DINA) espiaba a la iglesia católica, hacía una lista de 'curas marxistas.' Adicionalmente, DINA infiltraba a

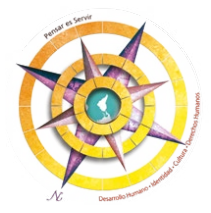


la iglesia por el Comité de Cooperación para la Paz en Chile (Comité Pro Paz). El agente, Alberto Palacios González era responsable y el cardenal confiaba en él. Palacios traicionaba al Cardenal Raúl Silva Henríquez y ofreció viajar a Argentina huir de Pinochet.

El régimen militar también utilizaba la inspección de las oficinas de arzobispos, las residencias de monjas, curas y parroquias, según Eli Michael Allen (2009). Mario I. Aguilar (2003) añade su voz al debate. Destaca que el ejército inspeccionó la casa de Raúl Silva Henríquez para un objeto plástico que cayó de un avión. Este objeto nunca ha sido hallado. No obstante, este método de intimidación no paró al cardenal Raúl Silva Henríquez y a los otros miembros de la iglesia católica de denunciar las violaciones de derechos humanos por Pinochet.

La censura es otro método que Pinochet usaba. En América Latina, la iglesia católica ocupaba una posición muy alta en la sociedad. Es la voz de denuncia de violaciones de derechos humanos y provee ayuda social al pueblo. Allen (2009) revela que había censura y clausura de las publicaciones y la transmisión de la iglesia católica por Pinochet. Esta no solo era en los medios de comunicación como radio y periódico. Pinochet extendía su colonialidad del poder por la censura de la televisión. Pamela Lowden (1993) menciona que, con la censura de los medios de comunicación, Pinochet y su régimen refutaban dar acceso a la televisión al cardenal Silva. Allen (2009) también menciona que Pinochet quería la censura de los discursos del obispo católico. Después del golpe de estado, Pinochet quería que, por adelantado, el obispo presentara a la junta militar, para la aprobación, su Te Deum. El tema de Te Deum era la reconstrucción de la patria. -Pinochet tenía miedo de que el obispo denunciaría su junta militar y llamaría a un fin de su reino de terror.

La propaganda es otra manera en que Pinochet y su régimen militar trataban de desacreditar el Comité Pro Paz en Chile. Lowden (1993) destaca que Pinochet y su régimen militar pusieron en marcha una campaña de propaganda contra este Comité. Pinochet y su régimen militar tenían miedo del trabajo y la eficacia de este Comité.

Métodos violentos también formaban parte de la estrategia de intimidación de Pinochet. Escalante (2006) señala las estadísticas de tortura, matanzas y expulsiones en 1974 por 
el ejército chileno y Pinochet a los miembros de la iglesia católica. En 1974, cuatro (4) sacerdotes fueron interrogados, doce (12) detenidos y liberados, catorce (14) detenidos, diez (10) salieron del país, dieciocho (18) fueron expulsados y un sacerdote murió. Es decir, al año siguiente del golpe de Estado, al menos cincuenta y nueve (59) sacerdotes habían sufrido por el reino de terror de Pinochet y su ejército. Allen (2009) ofrece una perspectiva muy diferente a Escalante. Allen (2009) opina que semanas después del golpe de Estado, cuarenta y cinco (45) sacerdotes fueron expulsados y varios matados en las semanas iniciales del golpe. Ocurrieron varias muertes, detenciones y torturas de sacerdotes en los años siguientes (Allen, 2009).

Brian Smith (1986) ofrece su perspectiva de la represión de la iglesia católica con estadísticas más alarmantes que los otros autores. Smith (1986) demuestra que los dos primeros años después del golpe, hubo una caída en el número de sacerdotes. El declive era de trescientos ochenta (380) sacerdotes que representaban quince por ciento (15\%) de la población de sacerdotes en Chile (Smith, 1986). La mayoría de sacerdotes era extranjera. Adicionalmente, Smith (1986) destaca la no renovación de permisos por el gobierno. Se puede establecer un vínculo posible con la caída en el número de sacerdotes y la represión por Pinochet y su ejército.

Pinochet no estaba satisfecho de intimidar a los sacerdotes y los seguidores de la religión católica por tortura, vigilancia y muerte. Este líder utilizaba el método de infiltrar a la universidad y la escuela católica en Chile. Smith (1986) destaca la intervención militar en las escuelas primarias católicas. Había censura de libros que podían adoctrinar a estudiantes, limitación de los consejos de padres en su alcance de actividades, reducción de subsidios y disminución de servicios de nutrición.

Una pregunta muy importante en esta investigación es: ¿cuál era la relación entre la iglesia evangélica/ protestante y Pinochet? David Oviedo Silva (2006) muestra la buena relación entre Pinochet y la iglesia evangélica. Oviedo Silva (2006) menciona que había tratamiento preferencial por el régimen militar a la iglesia evangélica, resultado de su diferente perspectiva a la represión en Chile.

Dos características de su punto de vista por la iglesia evangélica que promovían este tratamiento eran individualismo y sumisión al sistema económico- político (Oviedo Silva,

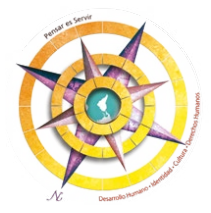


2006). La iglesia evangélica en Chile, en vez de promover colectivismo y oposición al régimen de Pinochet, promovía valores opuestos para tratar de salvaguardar su existencia en Chile y aumentar sus números. La iglesia evangélica representaba la sociedad individualista, 'progreso' y 'productividad'. Por otro lado, la iglesia católica simbolizaba la sociedad colectivista, tradición y 'oprimida'. Esta investigadora opina que, lo de la iglesia evangélica era un caso de la supervivencia del más apto.

Smith (1986) presenta una perspectiva muy diferente a Oviedo Silva (2006) sobre la relación entre Pinochet y la iglesia protestante. Smith (1986) menciona que hay miembros de la iglesia protestante que habían enfrentado la represión por Pinochet y su ejército. El resultado fue que los pastores extranjeros fueron expulsados o experimentaron estrés después del golpe de Estado. Estos pastores que habían experimentado la represión estaban de acuerdo con los objetivos de Allende y algunos eran miembros activos de Cristianos para el Socialismo.

\section{Múltiples perspectivas de la iglesia católica}

La iglesia católica no funcionaba como una voz/ una unidad. Había católicos que estaban a favor del socialismo y otros que oponían esta ideología política. Ignacio Gaete Lagos (2013) menciona las múltiples perspectivas de la iglesia católica en Chile. Los miembros en contra del socialismo habían criticado los fundamentos dogmáticos y doctrinarios de este (Gaete Lagos, 2013). Para estas personas, el socialismo estaba en contra de la libertad religiosa, los marxistas eran ateos y antirreligiosos y opinaban que la religión era “... el opio del pueblo". Los católicos no socialistas creían que el golpe de Estado por Pinochet era la única manera de "...purgar el pecado religioso en el cual la sociedad chilena estaba encontraba inmersa, siendo el medio más idóneo para trabajar por la construcción de la paz" (Gaete Lagos, 2013, p.11). Gaete Lagos (2013) también destaca la razón por la cual algunos católicos apoyaban a Pinochet. Según este para obtener el bien común y unidad nacional en Chile. Había un reconocimiento del valor espiritual y moral de los militares y civiles para salvar su país del caos.

\section{Denuncias de la iglesia católica}

La buena relación entre la iglesia católica y el Estado sufrió una ruptura con el golpe en Chile por Pinochet y su régimen. La iglesia católica muy temprano denunciaba a la dictadura 
militar. Stephen Bowers (1988) destaca que, en el año 1975, la iglesia católica estaba en contra de la dictadura militar en Chile. La iglesia no permanecía en el margen de la sociedad a vanguardia como denunciante de las acciones de Pinochet. Bernardo Guerrero Jiménez (1997) enfatiza que la declaración del Comité Permanente de Episcopado servía como una denuncia de la doctrina de la seguridad nacional y provocaba la brecha entre la iglesia católica y el régimen militar. "La iglesia no puede permanecer pasiva o neutral a esta situación. El legado que ella ha recibido de Cristo demanda que ella hablar a favor de la dignidad humana y por una efectiva protección de la libertad y derechos de las personas" (Guerrero Jiménez, 1997, p. 50). Esta declaración fue hecha en Santiago de Chile, en agosto de 1976.

La iglesia católica es una organización religiosa con mucha influencia. Veit Strassner (2006) destaca este hecho. Strassner (2006) opina que la iglesia católica tenía canales de influencia en el ámbito político y social para defender sus intereses. Estos medios de influencia son: las apelaciones a los gobernantes, la opinión pública (declaraciones y cartas pastorales), las acciones concretas y las relaciones de influencia de determinados funcionarios eclesiásticos, la posibilidad de excomunicación y los medios de comunicación eclesiásticos.

La respuesta de la iglesia católica a la represión era notable. Una de las maneras en que la iglesia católica podía funcionar como una contracultura era con la implementación de sus programas sociales. Johanna Marris (2009) revela que la iglesia católica creaba los centros de salud para personas con heridas de las protestas, los programas sociales que enfocan en los pobres y funcionaba como un refugio para personas afectadas a la represión de Pinochet y su ejército. Lo notable es que Marris (2009) destaca que no había discriminación por la iglesia católica y, cuando personas necesitaban protección, sin importar su creencia, la iglesia católica podía ofrecer protección a causa de su posición de prestigio en la sociedad chilena.

En el proceso de denuncia, la iglesia católica nunca funcionaba como una organización sumisa. Strassner (2006) destaca una de las más importantes tácticas de la iglesia católica en Chile. En su labor de denuncia de las violaciones de derechos humanos por Pinochet y su régimen, la iglesia católica juntaba información, documentaba y hacía

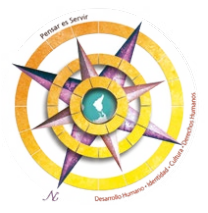


públicos los casos de violaciones de derechos humanos (Strassner, 2006). Lowden (1993) añade su voz al debate y menciona que la información sobre las violaciones de derechos humanos fue mandada a los obispos. Estos obispos enviaban esta misma información a las comisiones de derechos humanos de Organización de Estados Americanos (OEA) y a la Organización de Naciones Unidas (ONU).

El establecimiento del Comité de Cooperación para la Paz en Chile (COPACHI) también formaba parte de la denuncia por la iglesia católica a la dictadura de Pinochet. Melissa L. Mann (2003) menciona que COPACHI era una iniciativa común entre la iglesia católica y las iglesias protestantes. Los miembros de COPACHI incluyeron: la iglesia católica, judía, luterana, metodista, pentecostal, bautista, presbiteriana y ortodoxa (Mann, 2003). El objetivo de COPACHI era trabajar en conjunto contra la represión militar ilimitada. Los miembros de estas iglesias reconocían que no había personas que pudieran escapar de la represión de Pinochet y su régimen. Su sola solución era unidad porque con la unidad, hay fortaleza. A pesar de los esfuerzos de COPACHI para ayudar a los chilenos oprimidos, la organización fue disuelta por el cardenal
Raúl Silva Henríquez. Mann (2003) destaca que la razón para la disolución de COPACHI fue la presión militar. No obstante, la Vicaría de la Solidaridad fue creada por Cardenal Silva Henríquez para reemplazar COPACHI en 1976. Tal como COPACHI, la Vicaría de la Solidaridad ofrecía asesoramiento legal y protección de derechos humanos. La Vicaría consistía en tres departamentos: el departamento legal, el departamento de zonas y el departamento de la revista Solidaridad (Mann, 2003).

Un abandono de un cargo por un líder religioso servía a la denuncia de Pinochet. Strassner (2006) enfatiza que había abandono del cargo de gran canciller de la Universidad Católica por el predecesor del cardenal Juan Francisco Fresno, posiblemente el cardenal Raúl Silva Henríquez. Este abandono era resultado de la intervención de las Fuerzas Armadas en el ámbito universitario (Strassner, 2006). Esta era una manera de protestar contra la colonialidad del poder, la colonialidad del ser y la colonialidad del saber de Pinochet y su régimen militar.

\section{Pinochet y el Papa Juan Pablo II}

El jefe de la iglesia católica, el papa, desempeñaba un gran rol en la denuncia de Pinochet. Usualmente, el 
papa ofrece sus opiniones en asuntos internacionales que aquejan a los ciudadanos y sus seguidores. En su discurso en el Estadio Nacional durante su visita a Chile, el papa Juan Pablo II denunció las políticas de represión y regresión de Pinochet. Patricio Aylwin Azócar (1998), el presidente de Chile y sucesor de $\mathrm{Au}-$ gusto Pinochet menciona la denuncia por Juan Pablo II, quien utilizó la historia bíblica de la resurrección de la hija de Jairo.

Recordando el episodio evangélico de la resurrección de la hija de Jairo, dijo a los jóvenes y a todos los chilenos que este mundo 'que parece como si sucumbiera bajo el impulso desgarrador del odio, de la violencia y de la injusticia; [...] este mundo que es el vuestro, NO ESTÁ MUERTO, SINO ADORMECIDO.' Y repitiendo las palabras de Jesús a la niña dormida: 'Contigo hablo, levántate', los invitó a trabajar por una sociedad más justa y les dijo que "la fe en Cristo no enseña ... que vale la pena defender al inocente, al oprimido y al pobre, que vale la pena sufrir para atenuar el sufrimiento de los demás". (Aylwin Azócar, 1998, p. 324)

El papa Juan Pablo II rechazó la violencia y estaba a favor del “... amor universal, paciente y generoso" (Aylwin Azócar, 1998, p. 325).
Aylwin Azócar (1998) cree que este discurso del papa Juan Pablo II servía como una fuente de esperanza a los chilenos. "El mensaje del Papa levantó nuestro espíritu y nos dio una nueva perspectiva, menos unilateral, más amplia y humana, para proseguir la lucha" (Aylwin Azócar, 1998, p. 327).

\section{Conclusiones}

La iglesia católica chilena funcionaba como un contrapuesto y balance durante la administración pinochetista. En muchas ocasiones, la iglesia intervenía para restaurar la paz en un país que experimentaba episodios de tribulación y, por eso, cumplía su obligación bíblica expuesta en Mateo 5:9: “¡Dichosos los que hacen la paz, porque serán llamados hijos de Dios!" (Grupo Nelson, 2008, p. 6).

Otra bienaventuranza según Mateo 5:10 que sirvió para fortalecer la iglesia católica chilena durante los años de dictadura era: “¡Dichosos los que sufren persecución por ser justos, porque el reino de los cielos les pertenece!" (Grupo Nelson, 2008, p. 6). La persecución duraba diecisiete años, pero la resistencia y supervivencia de la iglesia duraba muchos más. La esperanza del reino de cielos prevenía a la iglesia católica de transformarse en una organización

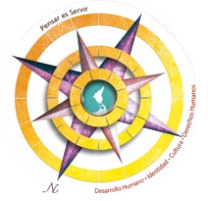


religiosa y terrorista. Esta esperanza provocaba simultáneamente la transformación de la iglesia de subcultura a contracultura.

Este organismo religioso contribuyó al fin de la dictadura de Pinochet y muestra la fortaleza de religión que puede vencer al político. La iglesia católica denunciaba el plebiscito. Strassner (2006) menciona que antes de las elecciones, los obispos en la iglesia católica reclamaban un voto consciente de los ciudadanos y una campaña que fuera orientada al bien común. Adicionalmente, había una declaración que denunciaba a Pinochet. Esta declaración era por una transición en paz que reclamó el respeto por la dignidad humana y por los derechos humanos. Los obispos, en esta declaración, también se pronunciaron contra el odio y el revanchismo: "¡Dichosos los que lloran, porque serán consolados!" (Mt. 5,4) (Grupo Nelson, 2008, p. 6.) La iglesia católica había llorado por muchos años y la caída de Pinochet era su gran consolación.

Los curas y los seguidores enfrentaban muchos retos para cumplir su obligación; pero nunca rendían sus esfuerzos, a pesar de los mecanismos de control y miedo utilizados por el dictador, Augusto Pinochet. La participación de la iglesia católica chilena, hasta hoy, es una fuente de esperanza y fortaleza para otros países que están enfrentando retos con dictadores. Por eso, la religión desempeña un gran rol en el avance de un país.

\section{Bibliografía}

Aguilar, M. I. (2003). Cardinal Raúl Silva Henríquez, The Catholic Church and the Pinochet Regime. The Catholic Historical Review, 89(4), 712-731.

Allen, E. M. (2009). From Private Diplomacy to Public Denunciation: The Catholic Church in Pinochet's Chile [Tesis de Licenciatura]. Wesleyan University, https://www.google.com/url?$\mathrm{sa}=\mathrm{t} \&$ source=web\&rct=j\&url=http:// wesscholar.wesleyan.edu/etd_hon_ theses $/ 257 / \&$ ved $=2$ ahUKEwiZg73 mw MDlAhXHq1 kKHSFtCeUQFjABegQIAxAB\&usg=AOvVaw2-yXzUJTjbqmxDM8BCdxCk

Arciniegas, G. (1956). Entre la libertad y el miedo. Editorial Sudamericana.

Aylwin Azócar, P. (1998). El reencuentro de los demócratas del golpe al triunfo de No. Ediciones B Chile.

Bowers, S. (1988). Pinochet's Plebiscite and the Catholics: The Dual Role of the Chilean Church. World Affairs, 150(2), 51-58.

Bustamente Olgún, F. G. (2009). La participación de las Comunicaciones Eclesiales de Base en la regeneración de la sociedad civil durante las dictaduras militares: Los casos de Chile 
y Brasil. Revista Cultura y religión, 3(1), 160-171.

Castro Gómez, S. (2000). Ciencias sociales, violencia epistémica y el problema de la 'invención del otro'. En S. Castro Gómez, La colonialidad del saber: Eurocentrismo y ciencias sociales. Perspectivas latinoamericanas (pp.88-98). CLASCO.

De Sousa Santos, B. (2006). Renovar la teoría crítica y reinventar la emancipación social. CLACSO.

De Sousa Santos, B. (2010). Descolonizar el saber, reinventar el poder. Ediciones Trilce.

Escalante, J. (2006, junio, 16). Cuando los servicios secretos de Pinochet infiltraron a la Iglesia. La Nación. https://rebelion.org/cuando-los-servicios-secretos-de-pinochet-infiltraron-a-la-iglesia/

Gaete Lagos, I. (2013). Capitalismo, marxismo y derechos humanos: El discurso político de la iglesia católica en Chile, 1970-1980. Manuscrito en preparación. Programa de Historia de las Ideas Políticas en Chile, Universidad Diego Portales.

Grosfoguel, R. y Castro Gómez, S. (2007). El giro decolonial. Reflexiones para una diversidad epistémica más allá del capitalismo global. Siglo del Hombre Editores; Universidad Central, Instituto de Estudios Sociales Contemporáneos y Pontificia Universidad Javeriana, Instituto Pensar.

Grosfoguel, R. (2008). Para un pluri-versalismo transmoderno decolonial. $R e$ vista Tabula Rasa, 9, 199-215.
Grupo Nelson. (2008). Nueva Biblia al Día. Grupo Nelson.

Guerrero Jiménez, B. (1997). Política y religión en la prensa de Iquique. Revista de Ciencias Sociales, 7, 48-61.

Jiménez, J. (1997). Crónicas de disidencia: Contracultura y globalización en América Latina. Revista de Filosofía Universidad de Costa Rica, 35(86),169-183.

Lowden, P. (1993). The Ecumenical Committee for Peace in Chile (1973-1975): The Foundation of Moral Opposition to Authoritarian Rule in Chile. $\mathrm{Bu}$ lletin of Latin American Research, 12(2), 189-203. https://www.google. com/url?sa=t\&source=web\&rct=j\&url=https://www.jstor.org/stable/ pdf/3338147. pdf\&ved=2ahUKEwjtnZeiwMDIAhXEjVkKHYoGD_oQFjAAegQIAhAB\&usg=AOvVaw2ndBpDhzQk4c-Jk5hHbm9C

Mann, M.L. The Father, The Son and Saint Joseph the Worker: The Chilean Church and Organized Labour. Manuscrito en preparación. 2003 meeting of the Latin American Studies Association. 27-29 de marzo de 2003. https://www.semanticscholar. org/paper/THE-FATHER\%2C-THESON\%2C-AND-SAINT-JOSEPHTHE - W OR K E R \% 3 A - M a n $\mathrm{n} / 473$ e $54077 \mathrm{~d} 098171 \mathrm{ab}$ 43f14201a225685301f473

Marris, J. (2009). The Church in Pinochet's Chile: Agent for Change? [Tesis de maestría]. University of London, United Kingdom. https://sas-space. sas.ac.uk/2300/

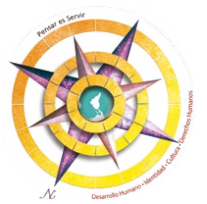


Ortúzar Madrid, P., Tomic López, C. y Huneeus Valenzuela, S. (2009). El mesianismo político de Augusto Pinochet y la lucha por el espacio sacrificial. Revista Temas Sociológicos, 13, 231-247.

Oviedo Silva, D. (2006). Modernidad y tradición en el pentecostalismo latinoamericano. Alcances socio-políticos en el Chile actual. Historia Actual Online, 11, 21-31. https://www.researchgate. net/publication/40905820_Modernidad_y_tradicion_en_el_pentecostalismo_latinoamericano_Alcances_ socio-politicos_en_el_Chile_Actual

Ramis, Á. (septiembre de 2013). Las iglesias y la dictadura chilena. Le Monde diplomatique. https://www.lemondediplomatique.cl/2013/09/las-iglesias-y-la-dictadura-chilena.html

Sjørup, L. (2006). Pinochet as protector and martyr for Christianity in Chile. Nordic Journal of Religion and Society, 19(2), 43-55.

Smith, B. (1986). Old Allies, New Enemies: The Catholic Church as Opposition to Military Rule in Chile, 1973-1979. En J. Samuel y A. Valenzuela (Eds.), Military Rule in Chile: Dictatorship and Oppositions (pp. 270-303). John Hopkins Press.

Stewart-Gambino, H. (2005). Las pobladoras y la Iglesia despolitizada en Chile. América Latina Hoy, 41, 121-138.

Strassner, V. (2006). La Iglesia chilena desde 1973 a 1993: De buenos samaritanos, antiguos contraherentes y nuevos aliados. Un análisis politológico. Teología y Vida, 47, 76-94. 